\title{
Characterization of Friction-Stir Welded Joints of AA1100 by Factorial Design Based Hierarchical Regression Model
}

\author{
Pallavi N. Senapati*, Rajat K. Bhoi \\ Department of Mechanical Engineering, ITER, SOADU, Bhubaneswar 751030, India
}

Corresponding Author Email: npallavisenapati@soa.ac.in

https://doi.org/10.18280/acsm.440406

Received: 21 February 2020

Accepted: 14 May 2020

\section{Keywords:}

friction stir welding, full factorial design, design of experiments, hierarchical regression analysis, tensile strength, average grain size

\begin{abstract}
The present study investigates the effect of process parameters of friction stir welding (FSW) process on the resulting microstructure and mechanical properties of the welded joints of AA1100 aluminium rolled plates. Experiments are conducted as per the scheme of full factorial design. The effect of tool rotation speed (TRS), welding speed (WS) and plunge depth (PD), which are the process parameters responsible to affect microstructure and mechanical properties of the joint, are investigated. Analysis of variance (ANOVA) has been conducted and the results indicate that the rotational speed of the tool is the most significant parameter with a p-value of 0.05 . The effect of processing parameters on tensile strength has been studied by developing a mathematical equation by using hierarchical regression analysis (HRA). The HRA results indicate that there exists a correlation among the process parameters. The TRS being the most significant parameter is not the only factor responsible for attaining superior mechanical properties of the joint. The WS and PD are also important for the quality of welding that point to a strong interaction among the process parameters. The researchers and industrialists can be highly benefited by this welding technique as numerous enhanced properties can be achieved with minimum input.
\end{abstract}

\section{INTRODUCTION}

Aluminium and its alloys have found extensive engineering application due to their light weight, toughness and wear resistant properties. Though, it has excellent forming and machining characteristics, but exhibits low weldability during traditional fusion welding process. FSW has been established as the most suitable joining technique for aluminium structures because of its inherent features including high joint strength, minimum flaws in original material, less consumption of energy and lack of unsafe emissions. In comparision to other fusion welding techniques, FSW is a promising welding method in which the workpiece is joined is in semi-solid state; thereby no occurrence of recast and melting of the material [1]. Weld specimens are free from imperfections with excellent mechanical properties in various alloys of aluminium, even the alloys that were considered to be non-weldable [2]. Due to non-fusion process, FSW is observed to offer several advantages over fusion welding processes including deployment of a non-consumable rotating tool with exceptionally developed shoulder and pin. The rotating tool is forced into the adjoining ends of the plates and made to travel along the joint to be formed [3].

It is acknowledged that in any welding process, the main challenge involves selecting the correct welding parameters yielding excellent weld joint close to the required specification. Further, there are often better alternative parametric combinations that can be used if they can only be predetermined. This has motivated to revisit the problem of exploring improved parametric combination. In this context, the present work undertakes experiment as per full factor factorial technique. The parameters are chosen on the basis of literatures available and then the significance of these parameters is established by Fisher test of experimental data. Using hierarchical regression analysis, a polynomial expression is developed as best fit. The polynomial equation is utilized to determine optimal parametric combination to obtain improved welded joint. The effect of process parameters of friction stir welding (FSW) method on the resulting microstructure and mechanical properties of weld specimens are investigated.

From the literature, it is observed that the prediction parametric values accurately without consuming much time, resources and effort have attracted researchers' attention. Researchers have demonstrated use of various computational techniques, facilitating quick yet accurate results. In FSW most widely considered machining parameters are rotating speed of the tool (TRS), speed of welding (WS), axial thrust, and tool profile [4-22]. The tool profile is described further by shoulder diameter, pin diameter and hardness of the tool material [4]. The tool and machining parameters are responsible for the generation of heat that in turn affects the tensile strength of FSW joints. Therefore, in majority of research work, the effect of tool rotation speed, weld speed, and thrust force on tensile strength of weld region are investigated and reported. The research work develops empirical relations to determine tensile strength with different tool rotation speed, weld speed and thrust values usually selected from a range of values during experimentation. In order to develop such empirical relations varieties of statistical tool and computational techniques are employed. Fathi et al. [5] used full factorial experimental design and conducted two 
sets of experiments (for conventional FSW and underwater FSW) consisting of 9 runs each in order to study the mechanical properties of the joint. Underwater FSW showed improved properties as compared to conventional FSW.

One of the most widely adopted tools is response surface methodology (RSM). Researchers have conducted experiments as per scheme of design of experiment and then carrying out ANOVA test to establish the significance of controlled process parameters on tensile strength of welded joints. So as to minimize the number of experimental runs, Elangovan et al. [4], Jayaraman et al. [6], Rajakumar et al. [7], Palanivel and Mathews [8], Al-jarrah et al. [9], Elatharasan and Senthil kumar [10,11], Govind Reddy et al. [12], Vignesh and Padmanaban [13] and Shaik et al. [14] have used full factor factorial central composite design. Considering tensile strength as the objective, an empirical second order polynomial expression has been determined as best fit. The adequacy of best fit has also been established by ANOVA test. In central composite design usually the number of replicates at corner points is one and at center points are more than one. The value of sum squared error is determined from the replicates of center points and is assumed that sum squared error; an indicator of dispersion effect is same for the corner points also. Therefore, it may mislead the significance test. Further, to arrive at best fit polynomial expression hit and trial search is employed with reduced step size in each subsequent iteration till it reaches a satisfactory value. Results exhibit that tool rotation has maximum contribution to tensile strength among other parameters.

Few investigators [15-20] have used Taguchi based combinatorial optimization technique with the primary aim of finding the optimal process parameters to obtain maximum tensile strength. Suitable orthogonal array has been employed to conduct experiments with an aim to reduce the number of experiments. It is a quick method adopted to determine process optima by maximizing the ratio of signal to noise. The arithmetic mean is usually considered as signal and standard deviation as noise. But this method suffers from the limitation that optima are selected from among the levels of factors chosen to conduct experiment as per the orthogonal array. Thereby, it is likely to miss out actual optima. Further, in the absence of an empirical expression, gradient descent optima searching technique fails to be employed.

Prediction of tensile strength is also attempted by Ghetiya and Patel [21] employing back propagation variant of artificial neural network using log sigmoid transfer function well suited capture the nonlinear relationship of tensile strength with respect to process parameters. The training algorithm is based on gradient descent with momentum and adaptive learning rate. The quality of result is very much dependent on learning rate and momentum constant and being based on first order error optimization is prone to trapping in local minima and network paralysis. Further, a huge number of experimental data are necessary to design a satisfactory artificial neural network. Though, neural network-based models are better predictor of tensile strength but the study of behavior of interaction effect of multiple controlled parameters on tensile strength remains unexplored. In order to overcome such limitations Jayaraman et al. [6] and Lakshminarayan and Balasubramanyam [22] have developed neural net based on second order error optimization technique and considered the same data set in developing response surface by response surface modeling and have compared the results obtained from RSM model and ANN model.
It is observed that researchers have focused relatively more attention on study of the influence of process parameters and parametric optimization than micro-structural and mechanical properties correlation. One of the common findings is that tool rotation speed contributes $73.85 \%$ to the overall welding parameters. Microstructure and mechanical properties of FSW of AA1100 is optimized by the use of Taguchi's L9 orthogonal array [19]. Simulation of the evolution of grain structure of FSW workpiece was carried out by means of cellular automation technique. WS has a great influence in the grain size, hardness and tensile strength of the welded joint. Taguchi's L9 orthogonal array is employed to reduce the no. of experiments during dissimilar FSW of AA6061 and AA8011 [20]. Results reveal that TRS is major factor affecting the impact strength and WS has negligible influence on TS. It appears that very few literatures are available in characterization of AA1100 grade focusing on optimization of the process parameters considering simultaneously the structure-dependent properties of the fabrication by generating optimal grain size. Also, substantial amount of work concerning the microstructure of $1 \mathrm{xxx}$ aluminium series has not come to the notice of the present investigators. Though different investigators have tried to correlate various metallurgical aspects like reduction in grain size, changes in grain orientation, work hardening, formation of alumina in the FSW joint, dispersion of fine silicon particles, minimizing the casting defects (porosity, cold flake etc.), etc. with the welding parameters such as TRS, WS and PD [23]. It seems that sufficient report is not made available pertaining to the influence of the process parameters on the grain size developed in friction stir welding of aluminium alloy joints. The present work, therefore, is an attempt to study the effect of the machining parameters on the average grain size of the resultant weld which will increase the tensile strength of the weld. ANOVA test has been employed to find out the most significant process parameter and their mutual interactions. An empirical model has been developed by using Hierarchical regression analysis from the experimental data for the ultimate tensile strength of the weld.

\section{MATERIALS AND METHODS}

\subsection{Tool and workpiece material and fixture design}

Table 1. Chemical composition of AA 1100

\begin{tabular}{cc}
\hline Element & Percentage (\%) \\
\hline $\mathrm{Al}$ & 99.32 \\
$\mathrm{Cu}$ & 0.011 \\
$\mathrm{Mg}$ & 0.002 \\
$\mathrm{Si}$ & 0.22 \\
$\mathrm{Fe}$ & 0.38 \\
$\mathrm{Mn}$ & 0.015 \\
$\mathrm{Ti}$ & 0.014 \\
$\mathrm{Zn}$ & 0.003 \\
others & 0.03 \\
\hline
\end{tabular}

The workpiece material chosen is AA 1100 aluminium rolled sheets with $5 \mathrm{~mm}$ thickness. The composition of the material is shown in Table 1. The dimensions of the sheets cut for experiment are $100 \mathrm{mmx} 50 \mathrm{~mm}$. The tool material chosen for experiment is of tool steel having a square pin as shown in Figure 1(a). The shoulder diameter, pin length and the equivalent radius (diagonal of square pin) are taken as is 
$21 \mathrm{~mm}, 4.1 \mathrm{~mm}$ and $7 \mathrm{~mm}$ respectively. The fixture as shown in Figure $1(\mathrm{~b})$ is designed to restrict the vibrations and unnecessary movement of the workpiece. A groove of $50 \mathrm{~mm}$ is made for the workpiece. Four holes were made on the groove for fixing the dynamometer.

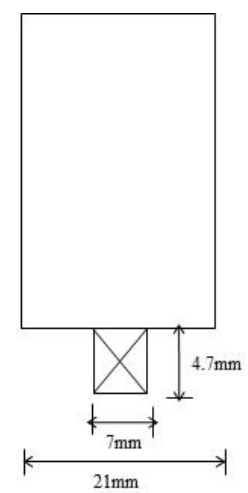

(a)

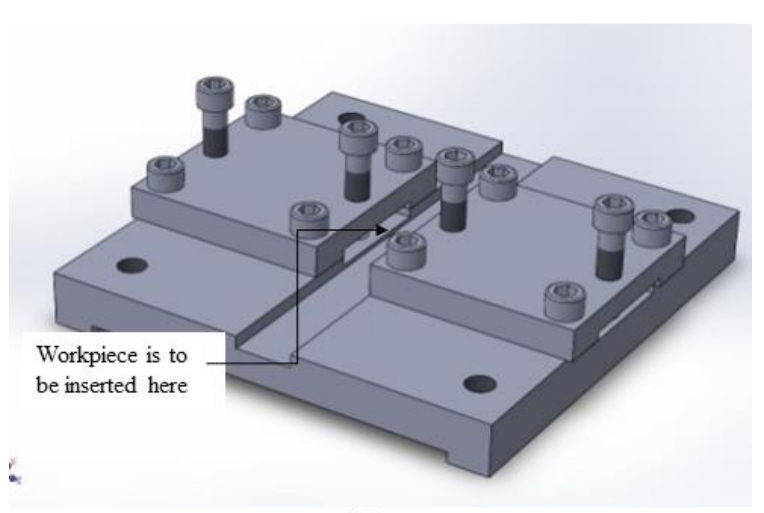

(b)

Figure 1. (a) Fixture; (b) Tool

\subsection{Experimental setup}

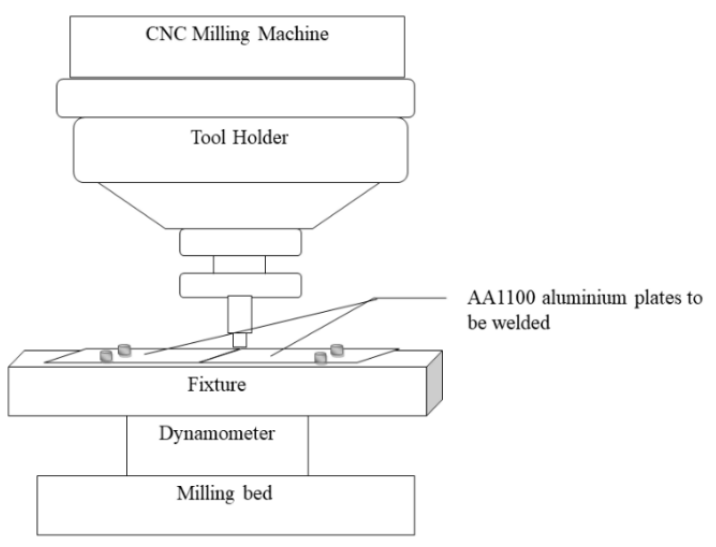

Figure 2. Experimental setup

Experiments have been conducted by using an external nonconsumable rotating tool where tool rotation speed, feed rate and plunge depth can be controlled very accurately. Tool rotation speed is varied from 1100 to $1500 \mathrm{rpm}$, welding speed is varied from 20 to $60 \mathrm{~mm} / \mathrm{min}$ and plunge depth from 0.1 to $0.5 \mathrm{~mm}$. The setup consists of a fixture which is clamped of the movable bed of the milling machine. Two aluminium plates are placed adjacent to each other on the fixture and fastened to restrict its movement. Tool is fixed to the tool holder. Torque and thrust measurement have been done using a multi- component dynamometer of make KISTLER model 9272. The experimental setup is shown in Figure 2. For each experimental run, three numbers of experiments have been conducted and the average of the output responses obtained in each run has been considered.

\subsection{Study of microstructure}

After the FSW process, the study of microstructure has been undertaken so as to observe the grain structure of various zones of the welded specimen. To accomplish this, friction stir welded samples are first cut along the cross section that included all the zones oriented perpendicular to the joint line. The specimens are then mounted and has been polished in order to get mirror finish followed by etching using Keller's reagent in order to expose the microstructure and is observed under optical microscope. The average grain size of BM, TMAZ, HAZ and NZ are measured.

\subsection{Mechanical tests}

The micro-hardness of the weld specimens has been evaluated to study the surface characteristics of the welded region and $\mathrm{BM}$. The specimens are prepared in the same method as discussed for the microstructure observations. Vicker's hardness profiles across the weld region, HAZ, TMAZ and BM were determined under a load of $50 \mathrm{~g}$ for $10 \mathrm{sec}$ across the centerlines of the specimens with a spacing of $2 \mathrm{~mm}$ on both sides from the weld centre using an automatic hardness tester. For tensile test, the welded work pieces have been reduced evenly to $4 \mathrm{~mm}$ thickness by milling and then tensile test specimens are cut as per Indian Standard ISI608. In order to confirm the tensile test, 3-point bend test is conducted. The weld specimens are cut as per Indian standard for 3-point bend test.

\subsection{Design of experiments}

In this study, a full-factor experimental design is introduced to optimize the process parameters to obtain maximum tensile strength of the joint. Full factorial method is most likely the common and spontaneous approach of the experimental design. Let us consider the simplest form of experimental design, that is, the 2-level full factorial design. It consists of ' $\mathrm{m}$ ' factors with 2 levels for each factor. The sample arrangement is specified by each feasible combination of the factors. Thus, the sample size is $S=2^{\mathrm{m}}$. Here, the number of factors is 3 . Hence the sample size is $\mathrm{S}=2^{3}=8$ number of experiments are to be conducted. The two levels are called high and low denoted by ' $h$ ' and ' $l$ ' or ' +1 ' and ' -1 ' respectively. The number replicates are three and the average of three replicates are considered for study of characterization purpose. The factors and the levels chosen for the experiment are given in Table 2. The full factorial method is regarded as the orthogonal experimental design because the scalar product of any two factors of any two columns is zero as given in Table 3.

Table 2. Factors and their levels

\begin{tabular}{cccc}
\hline Factor & Unit & $\begin{array}{c}\text { Low } \\
\text { Level }\end{array}$ & $\begin{array}{c}\text { High } \\
\text { Level }\end{array}$ \\
\hline Tool rotation speed & $\mathrm{rpm}$ & 1200 & 1400 \\
(TRS) & & & \\
Welding Speed (WS) & $\mathrm{mm} / \mathrm{min}$ & 40 & 60 \\
Plunge depth (PD) & $\mathrm{mm}$ & 0.1 & 0.3 \\
\hline
\end{tabular}


Table 3. $2^{3}$ Full factorial experimental design

\begin{tabular}{|c|c|c|c|c|c|c|c|c|}
\hline \multirow[t]{2}{*}{ Expt. No. } & \multicolumn{3}{|c|}{ Factor Level } & \multirow[t]{2}{*}{ Avg. UTS (z) } & \multicolumn{4}{|c|}{2 and 3 factor interactions } \\
\hline & $\operatorname{TRS}\left(\mathbf{x}_{1}\right)$ & $\mathbf{W S}\left(\mathbf{x}_{2}\right)$ & $\mathbf{P D}\left(\mathbf{x}_{3}\right)$ & & $\mathbf{x}_{1} \mathbf{X}_{2}$ & $\mathbf{x}_{1} \mathbf{x}_{3}$ & $\mathbf{x}_{2} \mathbf{X}_{3}$ & $\mathbf{x}_{1} \mathbf{X}_{2} \mathbf{X}_{3}$ \\
\hline 1 & -1 & -1 & -1 & $\mathrm{Zl}, 1,1$ & +1 & +1 & +1 & -1 \\
\hline 2 & -1 & -1 & +1 & $\mathrm{Zl,l,h}$ & +1 & -1 & -1 & +1 \\
\hline 3 & -1 & +1 & -1 & $\mathrm{Zl,h,1}$ & -1 & +1 & -1 & +1 \\
\hline 4 & -1 & +1 & +1 & $\mathrm{Zl,h,h}$ & -1 & -1 & +1 & -1 \\
\hline 5 & +1 & -1 & -1 & $\mathrm{Z}_{\mathrm{h}, 1,1}$ & -1 & -1 & +1 & +1 \\
\hline 6 & +1 & -1 & +1 & $\mathrm{Z}_{\mathrm{h}, \mathrm{llh}}$ & -1 & +1 & -1 & -1 \\
\hline 7 & +1 & +1 & -1 & $\mathrm{Z}_{\mathrm{h}, \mathrm{h}, \mathrm{l}}$ & +1 & -1 & -1 & -1 \\
\hline 8 & +1 & +1 & +1 & $Z_{\mathrm{h}, \mathrm{h}, \mathrm{h}}$ & +1 & +1 & +1 & +1 \\
\hline
\end{tabular}

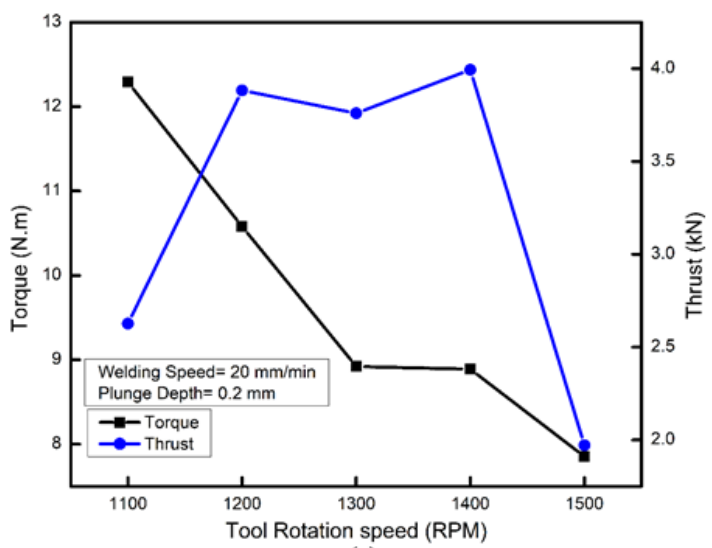

(a)

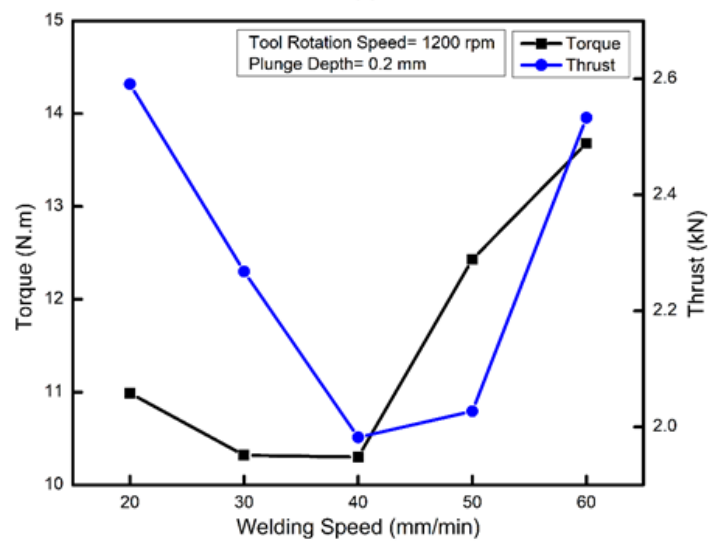

(b)

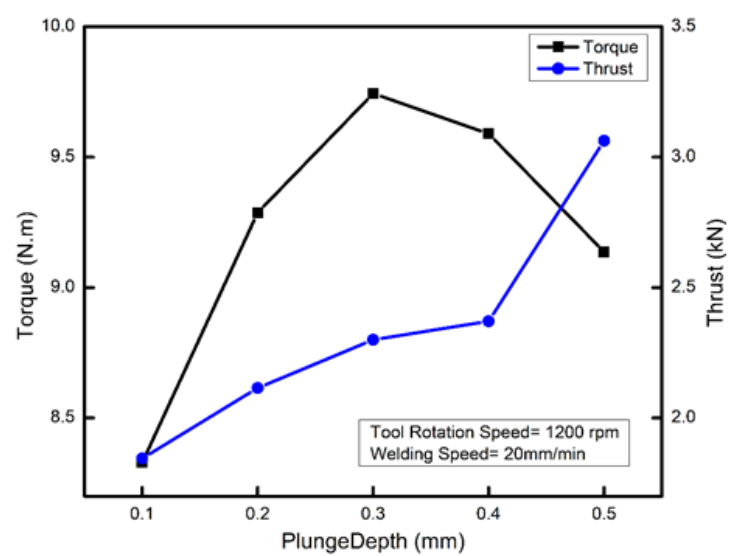

(c)

Figure 3. Torque and Thrust behaviour with (a) TRS; (b) Welding Speed(c) Plunge Depth

The general empirical model may be expressed as:

$\mathrm{y}=\mathrm{b}_{0}+\mathrm{b}_{1} \mathrm{x}_{1}+\mathrm{b}_{2} \mathrm{x}_{2}+\mathrm{b}_{3} \mathrm{x}_{3}+\mathrm{b}_{12} \mathrm{x}_{1} \mathrm{x}_{2}+\mathrm{b}_{13} \mathrm{x}_{1} \mathrm{x}_{3}+\mathrm{b}_{23} \mathrm{x}_{2} \mathrm{x}_{3}+\mathrm{b}_{123} \mathrm{x}_{1} \mathrm{x}_{2} \mathrm{x}_{3}+\xi$

where, $b_{0}=$ constant, $\xi=$ error.

\section{RESULTS AND DISCUSSION}

\subsection{Torque and thrust measurement}

During the FSW process, two forces namely the spindle torque and axial thrust are generated due to the tool rotation. The forces are affected by primary control parameters such as TRS, WS, shoulder and pin diameter of the tool. These output variables (torque and thrust) in turn affect the final characteristics of the weld. The TRS has a significant effect on the tool torque and thrust. It is evident from Figure 3(a) that increase in TRS leads to decrease in torque and thrust. This occurs due to the change in friction condition between the tool and workpiece that leads to a change in amount of heat generation. This heat results in softening of the workpiece, thus there is a decrease in torque and thrust. Also, it has been observed that for a particular TRS, torque is highly consistent during the primary plunging phase. Figure 3(b) shows the variation of torque and thrust with welding speed. Thrust is also a function of WS. When the WS is increased, the amount of heat generated in the localized region is decreased, resulting in a stiffer nugget zone under the tool. This stronger nugget zone leads to higher magnitudes of torque and thrust. This observation is in line with the results of Carl et al. [24]. Figure 3(c) shows the variation of torque and thrust with PD. Increase in PD causes tool digging into the work material resulting in higher thrust. Lower plunge depth leads to less force resulting in insufficient forging pressure to the workpiece that prevents solidification of the deformed BM. Torque does not have much variation with plunge depth.

\subsection{Observation from microstructure}

\subsubsection{Optical microscopy}

During friction stir welding the workpiece experiences massive plastic deformation and rapid heating and cooling, resulting in a complex microstructure formation. FSW specimen comprises of four different regions namely BM, HAZ, TMAZ and NZ, each having different grain size. BM structure commonly reveals an unrefined and irregular strip like grains that are elongated in the direction of rolling as shown in Figure 4 (a) HAZ, as shown in Figure 4 (c) is usual in all the welding methods which undergo only through the thermal cycles and there is no plastic deformation during welding and therefore no distinct variation in the grain size of HAZ and BM is observed. This observation is in good agreement with the microstructural results of Chen et al. and Liu et al. [25, 26]. TMAZ is the region below the tool shoulder which is commonly described as a transition region between $\mathrm{NZ}$ and HAZ. It is identified by a severely deformed pattern and a noticeable movement of original grains rotated in the direction of shoulder surrounding the nugget region. Though 
it experiences frictional heating, there occurs some change in its structure but the heat and deformation strain are not enough for complete recrystallization. Hence the formation of refined grains in TMAZ is not distinct like in NZ, and a well-defined boundary between the TMAZ and NZ can be achieved as shown in Figure 4 (b). From Figure 4 (d), the NZ can be described as a fine equiaxed grain structure because of extreme plastic deformation and heat generated due to friction during the process that result in fully refined and recrystallized grains. This is in line with Hamilton et al. [27].
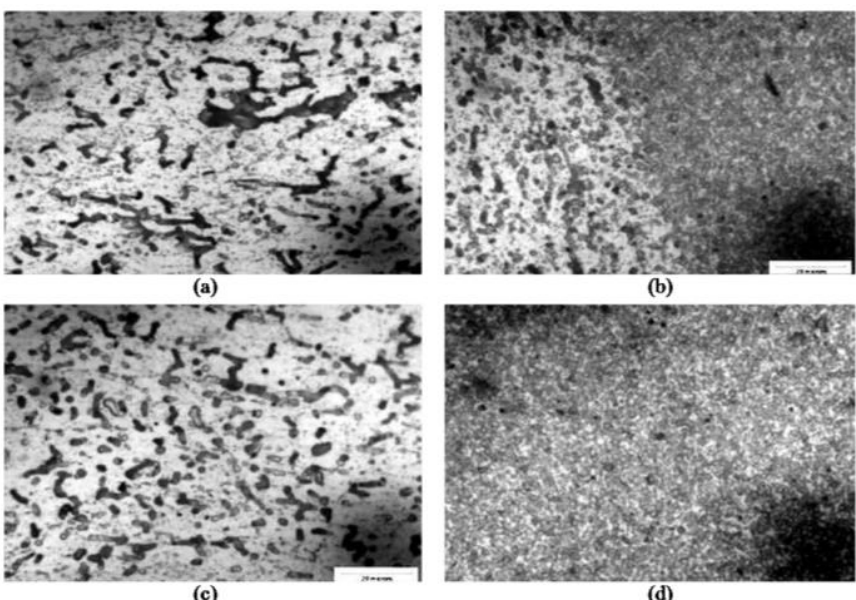

(c)

(d)

Figure 4. (a) Base Metal; (b) Thermomechanically Affected Zone; (c) Heat Affected Zone; (d) Nugget zone

\subsubsection{Grain size variation with process parameters}

The variation of average grain size with the process parameters is given in Figure 5 (a), Figure 5 (b) and Figure 5 (c). There is a decrease in average grain size with increasing TRS. This phenomenon takes place because with increase in TRS at a higher travel speed and constant plunge depth, more stirring action of the tool occurs due to which more heat input is given to the material and heat is dissipated from the material at a faster rate due to its high conductivity which results in the formation of finer equiaxed grains. It has been observed that with increase in WS the average grain size decreases. This occurs due to higher heat generation at lower WS which results in grain growth. Also, the deformation of grains in TMAZ is not severe for low welding speed because low welding speed leads to more dwelling time during FSW which generates more heat in stir zone of the workpiece and results in severe deformation. Liu et al. [26] also reported similar results. From Figure 5(c), an increase in average grain size with the increase in plunge depth at constant TRS and welding speed has been noted. As plunge depth increases, the contact area between the tool and workpiece is more because of which more friction occurs between the tool and workpiece and hence more heat is generated leading to grain growth in the joint.

\subsection{Microhardness test}

Sato and Kokawa stated that [28], like the microstructures of the weld region, the micro-hardness also reveals the mechanical behavior of the weld. Hence the tensile properties of the welds can be studied by the micro-hardness of the joints. The Hall-Petch relationship states that the microhardness in the nugget zone is supposed be greater than other zones due to its finely arranged equiaxed grains. But from the hardness profiles shown in Figure 6, the hardness value of TMAZ is higher than NZ possibly due to thermal cycles experienced by the FSW specimen which forms a softened region around the weld nugget. This softening around the nugget zone probably takes place due to thermal cycles that dissolve or coarsen the strengthening precipitates. Similar findings were reported by Chen et al. [25]. The microhardness value of NZ does not illustrate any significant difference in comparision with BM. The lowest hardness measured was the HAZ in the advancing side which is possibly caused by the coarsening of second phase particles during the welding. These results were in line with the findings of Liu et al., Sivaraj et al., Zhang et al. and Shukla et al. [26, 29-31]. The softest area is associated to the weld microstructure and fracture location of the specimen under loading. At lower TRS (1100 rpm) microhardness decreases progressively close to the periphery of NZ, increases a little to $38 \mathrm{HV}$ within centre NZ.

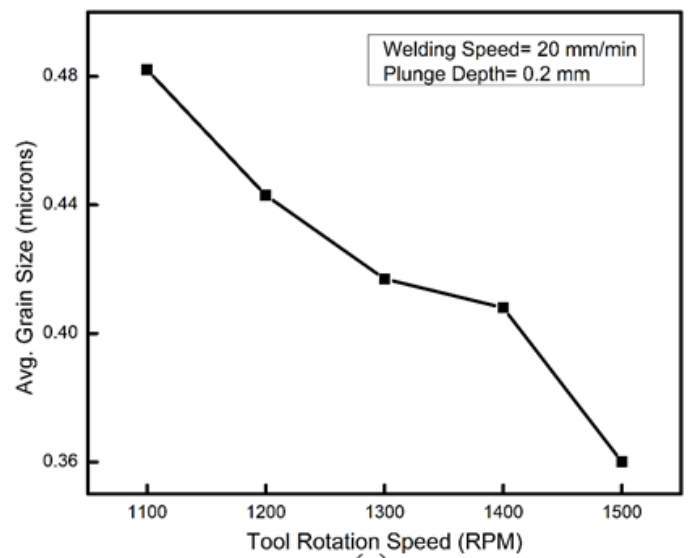

(a)

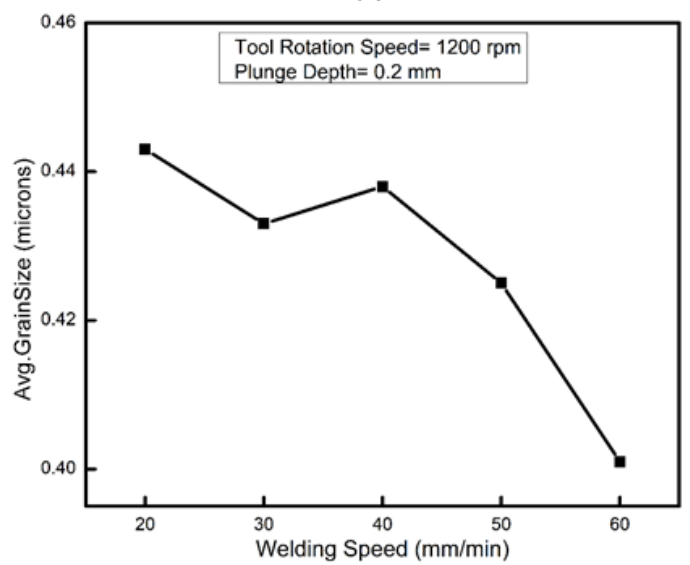

(b)

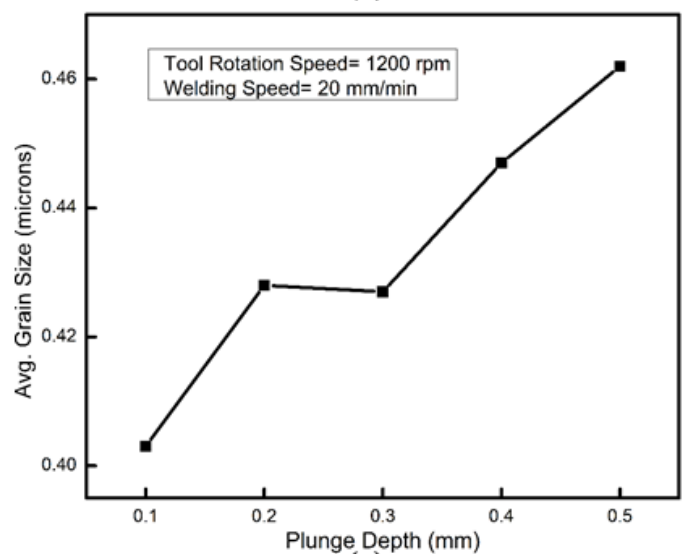

(c)

Figure 5. Variation of average grain size with (a) TRS; (b) WS; (c) Plunge depth 


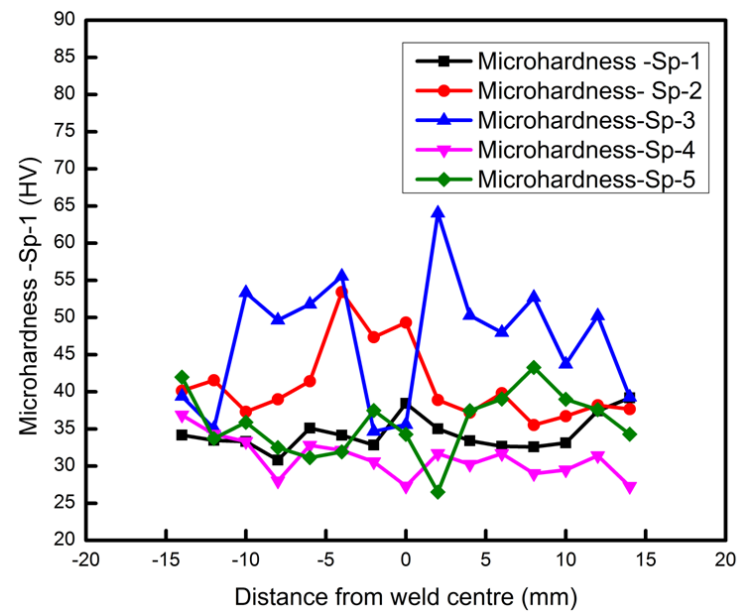

Figure 6. Microhardness profiles

\subsection{Tensile test results}

The most influencing parameter in FSW process is the tool rotational speed followed by welding speed. Plunge depth has very little effect on the welding process. Figure 7 (a) shows the variation of tensile strength, yield strength and elongation with tool rotation speed. With increase in TRS from $1100 \mathrm{rpm}$ to $1400 \mathrm{rpm}$, the tensile strength increases. When TRS is further increased to $1500 \mathrm{rpm}$, the tensile strength is decreased probably due to intense plastic deformation and high temperature leads to even finer grains than the sample at 1400rpm thus the hardness of the material increases and so does its brittleness. Specimen welded at $1100 \mathrm{rpm}$ shows very low tensile strength because of poor joint formation. The low TRS led to insufficient heating and stirring of material that resulted in improper joining of the workpieces. Sample welded at $1500 \mathrm{rpm}$ shows a decrease in tensile strength because increasing TRS leads to higher heat generation that changes the friction condition during welding making a lower material flow stress between tool and workpiece. Hence there has been formation of void defect in the joint. Yield strength shows similar behavior as the tensile strength for all the samples. Figure 7 (b) shows the behaviour of tensile strength with WS. Both tensile and yield strength values are seen to increase with the welding speed. However, noticeable changes in the elongation values could not be seen. This is because of the formation of more fine-grained structure with higher speeds of welding which could have restricted the plastic deformation of the material. This is in line with the findings of Liu et al. [32]. At low WS there is higher rate of heat accumulation within the material. Thus, the workpiece experiences high temperature for more time due to which rate of grain growth takes over the rate of nucleation. This results in the development of coarse grains thereby resulting in lower tensile strength. At high welding speed, higher rate of heat dissipation to the ambient occurs due to which there is less time at high temperature. Hence the rate of nucleation takes over and fine grains are formed resulting in higher tensile strength. Figure 7 (c) shows the variation of tensile strength with plunge depth. All the defect free joints show necking because friction stirred weld is a non-homogeneous composite that is comprises of various zones throughout the joint as well as the surfaces. These zones have different mechanical properties due to variation in grain size and therefore necking occurs in the least hardness region during tensile test, that is, HAZ in this case. Wang et al. and Hu et al. observed similar results [33, 34].

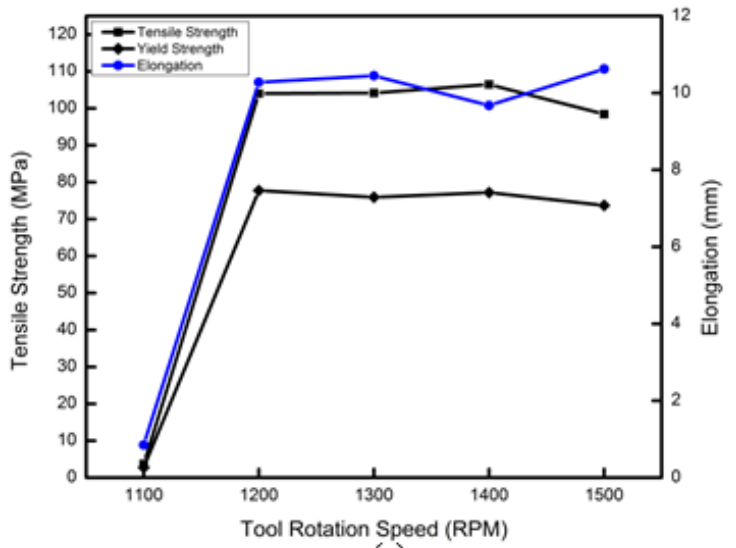

(a)

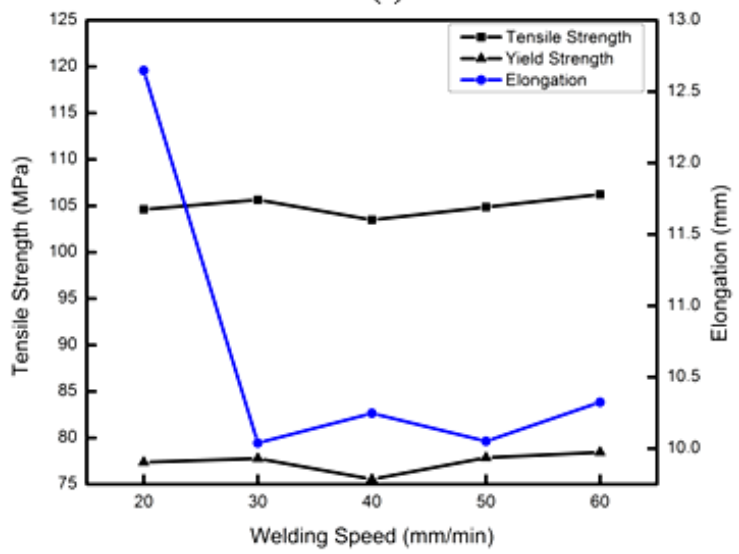

(b)

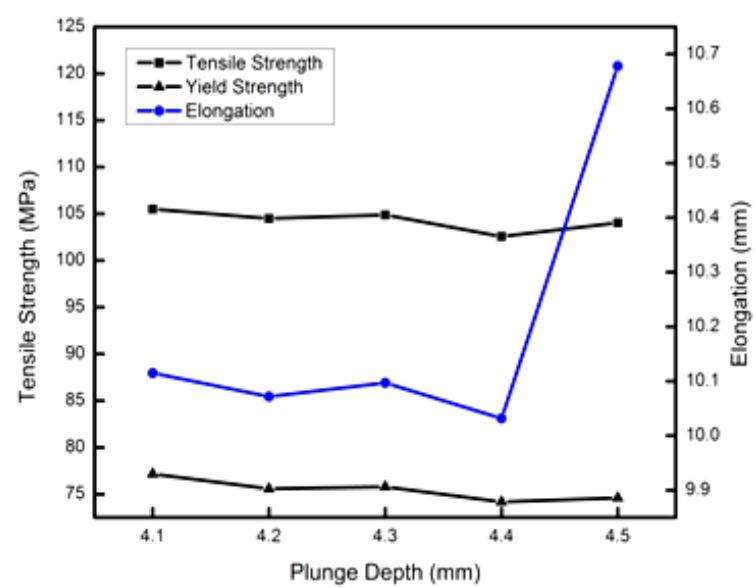

(c)

Figure 7. Variation of average Tensile Strength (a) TRS; (b) Welding speed; (c) Plunge depth

\subsection{Bend test results}

Three-point bend test was carried out as a confirmation for the tensile test results. The results obtained with various process parameters are given in Figure 8. Values obtained from the bend test were in excellent accordance with the tensile test results. Both the parent material and welded specimens present linear behavior during bending test except the specimen welded at $1500 \mathrm{rpm}$ in which the brittleness of the NZ increased and showed crack during the test. As the TRS was high, there was higher stirring action which leads to severe plastic deformation and grain refinement of the joint. As a result, the material lost its ductility. Also, void defect was formed which significantly affected the bending properties. Rest all specimens showed satisfactory results. 


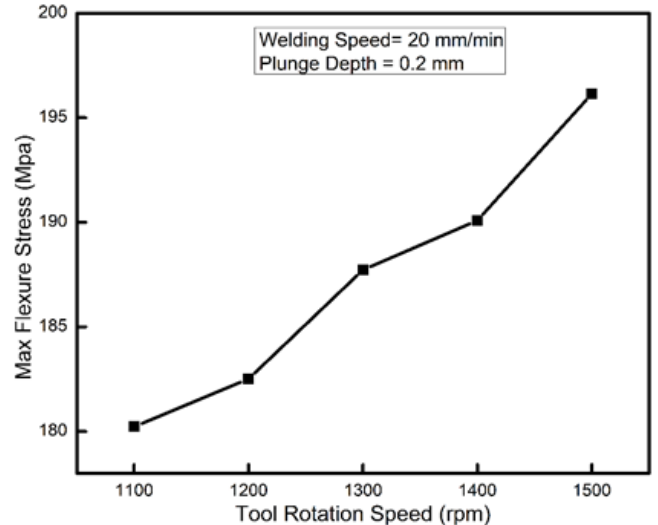

(a)

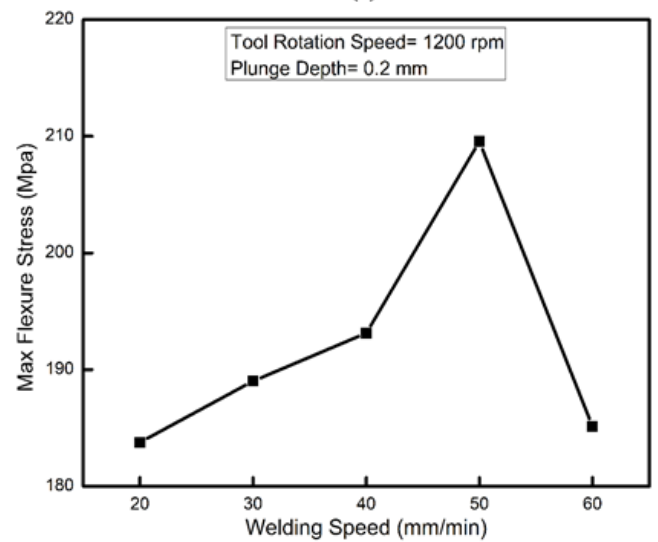

(b)

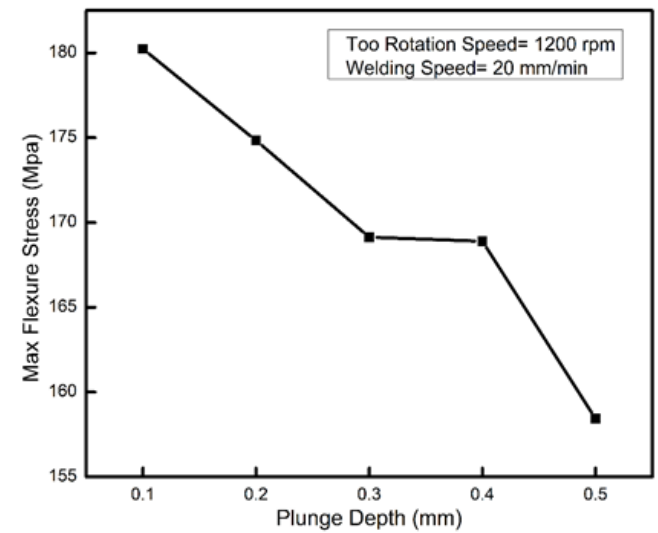

(c)

Figure 8. (a) Effect of TRS on flexure stress, (b) Effect of WS on flexure stress, (c) Effect of PD on flexure stress

\subsection{Analysis of variance (ANOVA)}

Analysis of variance test has been carried out to distinguish the most significant operating parameters that affect the ultimate tensile strength of the friction stir welded joints. Results show that the machining parameters chosen are greatly significant and their effect on the ultimate tensile strength of friction stirred welds is in the order of tool rotation speed, plunge depth and welding speed. Similar findings have been reported by Koilraj et al. [17] and Lakshminarayanan et al. [8]. Table 4 shows the analysis of variance test between subject effects. It can be seen that the p-value of tool rotation speed is 0.05 indicating it to be the most significant process parameter.

\subsection{Hierarchical regression analysis}

Hierarchical regression is a means to demonstrate if the factors involved in the experiment show a remarkable statistical variation in the output responses after accounting for all the other factors. This method is an attempt for the development of standard regression approximation by adding a regression to a regular model at second stage. Here hierarchical regression has been used to investigate data and find the most significant factor that affects the tensile strength of the joint. Another reason for conducting a hierarchical regression analysis in these research applications due to the high correlation among the independent variables (also known as regressors). When the correlated regressors are incorporated in the regression model at the same time, multi-collinearity arises [35]. Table 5 and Table 6 show the model summary and significance of process parameters respectively that are obtained using the SPSS software.

Table 6 shows that when all the three parameters, that is, TRS, WS and PD are entered, the significance of TRS is 0.05, WS is 0.114 and of PD is 0.097 . This indicates that the TRS solely is not responsible for a sound friction stir welded joint. The WS and PD also play a major role in welding. But among the three parameters, the TRS is the most significant one with the significance level of 0.05 . It can be inferred that the parameters are correlated to each other. Because with the absence of any single factor the other parameters become insignificant as shown in Sl. No. 1 and 2 in Table 6.

\section{CONCLUSIONS}

Friction stir welding of aluminium has found its applications in various industries because of its tremendous strength generations of the joint. In this paper, the behaviour of friction stir welding of AA 1100 aluminium alloy is studied through measurement of torque and thrust. The results obtained from the microstructural study and mechanical properties are:

(a) The microstructure of various welding zones has been studied and their average grain size has been measured. The average grain size of various zones measured is of the order $\mathrm{BM}>\mathrm{HAZ}>\mathrm{TMAZ}>\mathrm{NZ}$. Fracture occurred in the HAZ of the advancing side because of coarsened grains due to high heat input during welding.

(b) The grain size of the material is an important property that can either enhance or degrade the mechanical properties of the joint. The average grain size of the weld zone is strongly influenced by the rate of heat generated and the cooling rate. And these factors are the function of the process parameters. Hence to obtain a proper grain size and a sound weld, the process parameters have to be controlled.

(c) The ultimate tensile strength increases with increase in TRS and WS and the tensile test results were confirmed by the three-point bend test. All the welded samples showed an increase in tensile strength without losing its ductility except the sample welded at $1500 \mathrm{rpm}$ that showed brittle nature during bend test. Microhardness value of HAZ is observed to be minimum and of TMAZ is observed to be maximum among all the zones. Hardness value of NZ is marginally higher than BM.

(d) ANOVA results stated that the rotational speed of the tool is the most significant factor for welding with a p-value of 0.05. The hierarchical regression analysis inferred that the TRS has its significance only when WS and PD are also included in the model, indicating a strong correlation among the welding parameters. 
Table 4. Analysis of variance

\begin{tabular}{cccccc}
\hline \multicolumn{5}{c}{ Test of between-subject effects } \\
\hline \multicolumn{5}{c}{ Dependent variable= Ultimate Tensile Strength (UTS) } \\
\hline Source & Sum of Squares & Degrees of Freedom & Mean square & F-value & P-value \\
Corrected Model & $11.226^{\mathrm{a}}$ & 3 & 3.742 & 5.474 & 0.067 \\
Intercept & 265630.973 & 1 & 26563.973 & 38862.495 & 0.000 \\
Tool Rotation Speed & 5.265 & 1 & 5.265 & $7.703^{*}$ & 0.050 \\
Welding Speed & 2.773 & 1 & 2.773 & 4.057 & 0.114 \\
Plunge Depth & 3.188 & 1 & 3.188 & 4.664 & 0.097 \\
Error & 2.734 & 4 & 0.684 & & \\
Total & 265770.933 & 8 & & & \\
Corrected total & 13.960 & 7 & & \\
& a. R-squared=0.804 (Adjusted R-squared=0.657) *p=0.05<=0.05 & & \\
\hline
\end{tabular}

Table 5. Model summary

\begin{tabular}{ccccc}
\hline Model & R & R Square & Adjusted R Square & Std. Error of the Estimate \\
\hline 1 & $0.614^{\mathrm{a}}$ & 0.377 & 0.273 & 1.20381 \\
2 & $0.759^{\mathrm{b}}$ & 0.576 & 0.406 & 1.08830 \\
3 & $0.897^{\mathrm{c}}$ & 0.804 & 0.657 & 0.82676 \\
\hline a. Predictors: (Constant), Tool Rotation Speed \\
b. Predictors: (Constant), Tool Rotation Speed, Welding Speed \\
\multicolumn{2}{l}{ c. Predictors: (Constant), Tool Rotation Speed, Welding Speed, Plunge Depth }
\end{tabular}

Table 6. Coefficients

\begin{tabular}{|c|c|c|c|c|c|c|}
\hline & \multirow[t]{2}{*}{ Model } & \multicolumn{2}{|c|}{ Unstandardized Coefficients } & \multirow{2}{*}{$\frac{\text { Standardized Coefficients }}{\text { Beta }}$} & \multirow[t]{2}{*}{$\mathbf{t}$} & \multirow[t]{2}{*}{ Significance } \\
\hline & & B & Standard Error & & & \\
\hline \multirow[t]{3}{*}{1} & (Constant) & 47.077 & 5.549 & & 8.484 & 0.000 \\
\hline & TRS & 0.008 & 0.004 & 0.614 & 1.906 & 0.105 \\
\hline & (Constant) & 44.134 & 5.373 & & 8.214 & 0.000 \\
\hline \multirow[t]{3}{*}{2} & TRS & 0.008 & 0.004 & 0.614 & 2.108 & 0.089 \\
\hline & WS & 0.059 & 0.038 & 0.446 & 1.530 & 0.187 \\
\hline & (Constant) & 17.621 & 12.938 & & 1.362 & 0.245 \\
\hline \multirow[t]{3}{*}{3} & TRS & 0.008 & 0.003 & 0.614 & 2.775 & 0.050 \\
\hline & WS & 0.059 & 0.029 & 0.446 & 2.104 & 0.114 \\
\hline & PD & 6.313 & 2.923 & 0.478 & 2.160 & 0.097 \\
\hline
\end{tabular}

a. Dependent Variable: Tensile Strength

\section{REFERENCES}

[1] Oosterkamp, A., Oosterkamp, L.D., Nordeide, A. (2004). Kissing bond phenomena in solid state welds of aluminium alloys. Welding Journal, 83(8): 225-231.

[2] Zeng, W.M., Wu, H.L., Zhang, J. (2006). Effect of tool wear on microstructure, mechanical properties and acoustic emission of friction stir welded $6061 \mathrm{Al}$ alloys. Acta Metallurgica Sinica, 19(1): 9-19. https://doi.org/10.1016/S1006-7191(06)60018-5

[3] Mishra, R.S., Ma, Z.Y. (2005). Friction stir welding and processing. Materials Science and Engineering: R: Reports, 50(1-2): 1-78 https://doi.org/10.1016/j.mser.2005.07.001

[4] Elangovan, K., Balasubramanian, V., Babu, S. (2008). Developing an empirical relationship to predict tensile strength of friction stir welded AA2219 aluminum alloy. Journal of Materials Engineering and Performance, 7(6): 820-830. https://doi.org/10.1007/s1 1665-008-9240-6

[5] Fathi, J., Ebrahimzadeh, P., Farasati, R., Teimouri, R. (2019). Friction stir welding of aluminum 6061-T6 in presence of watercooling: Analyzing mechanical properties and residual stress distribution. International Journal of Lightweight Materials and Manufacture, 2(2): 107-115. https://doi.org/10.1016/j.ijlmm.2019.04.007

[6] Jayaraman, M., Sivasubramanian, R., Balasubramanian,
V., Lakshminarayanan, A.K. (2008). Prediction of tensile strength of friction stir welded A356 cast aluminium alloy using response surface methodology and artificial neural network. International Journal for Manufacturing Science and Production, 9(1-2): 45-60. https://doi.org/10.1515/IJMSP.2008.9.1-2.45

[7] Rajakumar, S., Muralidharan, C., Balasubramanian, V. (2010). Optimization of the friction-stir-welding process and tool parameters to attain a maximum tensile strength of AA7075-T6 aluminium alloy. Proceedings of the Institution of Mechanical Engineers, Part B: Journal of Engineering Manufacture, 224(8): 1175-1191. https://doi.org/10.1243/09544054JEM1802

[8] Palanivel, R., Mathews, P.K. (2012). Prediction and optimization of process parameter of friction stir welded AA5083- H111 aluminum alloy using response surface methodology. Journal of Central South University, 19(1): 1-8. https://doi.org/10.1007/s1 1771-012-0964-y

[9] Al-Jarrah, J.A., Swalha, S., Mansour, T.A., Ibrahim, M., Al-Rashdan, M., Al-Qahsi, D.A. (2013). Optimization of friction stir welding parameters for joining aluminum alloys using RSM. Advances in Theoretical and Applied Mechanics, 6(1): 13-26. http://dx.doi.org/10.12988/atam.2013.222

[10] Elatharasan, G., Kumar, V.S.S. (2012). Modelling and optimization of friction stir welding parameters for 
dissimilar aluminium alloys using RSM. Procedia Engineering, 38: 3477-3481 https://doi.org/10.1016/j.proeng.2012.06.401

[11] Elatharasana, G., Kumar, V.S.S. (2013). An experimental analysis and optimization of process parameter on friction stir welding of AA 6061-T6 aluminum alloy using RSM. International Conference On Design and Manufacturing, IConDM 2013, Procedia Engineering, 64: $1227-1234$ https://doi.org/10.1016/j.proeng.2013.09.202

[12] Reddy, A.G., Saketh, C., Padmanaban, R., Balusamy, V. (2013). Process parameter optimization for friction stir welding of dissimilar aluminum alloys. International Journal of Engineering Research and Technology, 2(10): 3281-3288, ISSN: 2278-0181

[13] Vignesh, R.V., Padmanaban, R. (2018). Artificial neural network model for predicting the tensile strength of friction stir welded aluminium alloy AA1100. SCICON 2016, Materials Today: Proceedings, 5(8): 16716-16723. https://doi.org/10.1016/j.matpr.2018.06.035

[14] Shaik, B., Gowd, G.H., Prasad, B.D. (2019). Experimental and parametric studies with friction stir welding on aluminium alloys. 1st International Conference on Manufacturing, Material Science and Engineering, Materials Today: Proceedings, 19(2): 372379. https://doi.org/10.1016/j.matpr.2019.07.615

[15] Lakshminarayanan, A.K., Balasubramanian, V. (2008). Process parameters optimization for friction stir welding of RDE-40 aluminium alloy using Taguchi technique. Transactions of Nonferrous Metals Society of China, 18(3): 548-554. https://doi.org/10.1016/S10036326(08)60096-5

[16] Jayaraman, M., Sivasubramanian, R., Balasubramanian, V., Lakshminarayanan, A.K. (2009). Optimization of process parameters for friction stir welding of cast aluminium alloy A319 by Taguchi method. Journal of Scientific and Industrial Research, 68(1): 36-43.

[17] Koilraj, M., Sundareswaran, V., Vijayan, S., Rao, S.R.K. (2012). Friction stir welding of dissimilar aluminum alloys AA2219 to AA5083 -Optimization of process parameters using Taguchi technique. Materials and Design, $\quad 42$ : 1-7. https://doi.org/10.1016/j.matdes.2012.02.016

[18] Bozkurt, Y. (2012). The optimization of friction stir welding process parameters to achieve maximum tensile strength in polyethylene sheets. Materials and Design, 35: 440-445. https://doi.org/10.1016/j.matdes.2011.09.008

[19] Shojaeefard, M.H., Akbari, M., Khalkhali, A., Asadi, P., Parivar, A.H. (2014). Optimization of microstructural and mechanical properties of friction stir welding using the cellular automaton and Taguchi method. Materials and Design, 64: 660-666 https://doi.org/10.1016/j.matdes.2014.08.014

[20] Elanchezhiana, C., Ramnath, B.V., Venkatesan, P., Sathish, S., Vignesh, T., Siddharth, R.V., Vinay, B., Gopinath, K. (2014). Parameter optimization of friction stir welding of AA8011-6062 using mathematical method. 12th Global Congress on Manufacturing and Management, GCMM 2014, Procedia Engineering, 97: 775-782. https://doi.org/10.1016/j.proeng.2014.12.308

[21] Ghetiya, N.D., Patel, K.M. (2014). Prediction of tensile strength in friction stir welded aluminium alloy using artificial neural network. 2nd International Conference on Innovations in Automation and Mechatronics
Engineering, ICIAME 2014, Procedia Technology, 14: 274-281. https://doi.org/10.1016/j.protcy.2014.08.036

[22] Lakshminarayanan, A.K., Balasubramanian, V. (2009). Comparison of RSM with ANN in predicting tensile strength of friction stir welded AA7039 aluminium alloy joint. Transactions of Nonferrous Metals Society of China, 19(1): 9-18. https://doi.org/10.1016/S10036326(08)60221-6

[23] Rambabu, G., Naik, D.B., Rao, C.H.V., Rao, K.S., Reddy, G.M. (2015). Optimization of friction stir welding parameters for improved corrosion resistance of AA2219 aluminum alloy joints. Defence Technology, 11(4): 330337. https://doi.org/10.1016/j.dt.2015.05.003

[24] Sorensen, C.D., Stahl, A.L. (2007). Experimental measurements of load distributions on friction stir weld pin tools. Metallurgical and Materials Transactions B, 38(3): 451-459. https://doi.org/10.1007/s11663-0079041-6

[25] Chen, Z., Li, S., Hihara, L.H. (2015). Microstructure, mechanical properties and corrosion of friction stir welded 6061 Aluminium alloy, Hawaii Corrosion Laboratory, University of Hawaii at Manoa, Honolulu, HI 96822, USA.

[26] Liu, H.J., Hou, J.C., Guo, H. (2013). Effect of welding speed on microstructure and mechanical properties of self-reacting friction stir welded 6061-T6 aluminum alloy. Materials and Design, 50: 872-878. https://doi.org/10.1016/j.matdes.2013.03.105

[27] Hamilton, C., Dymek, S., Blicharski, M. (2008). A model of material flow during friction stir welding. Materials Characterization, $\quad$ 59(9): 1206-1214. https://doi.org/10.1016/j.matchar.2007.10.002

[28] Sato, Y.S., Kokawa, H. (2001). Distribution of tensile property and microstructure in friction stir weld of 6063 aluminum. Metallurgical and Materials Transactions A, 32A: 3023-3031. https://doi.org/10.1007/s11661-0010177-8

[29] Sivaraj, P., Kanagarajan, D., Balasubramanian, V. (2014) Effect of post weld heat treatment on tensile properties and microstructure characteristics of friction stir welded armour grade AA7075-T651 aluminium alloy. Defence Technology, 10(1): 1-8. https://doi.org/10.1016/j.dt.2014.01.004

[30] Zhang, Z., Xiao, B.L., Ma, Z.Y. (2013). Effect of segregation of secondary phase particles and " $S$ " line on tensile fracture behavior of friction stir-welded 2024AlT351 joints. Metallurgical and Materials Transactions A, 44(9): 4081-4097. https://doi.org/10.1007/s11661-0131778-8

[31] Shukla, A.K., Baeslack, W.A. (2009). Study of process/structure/property relationships in friction stir welded thin sheet $\mathrm{Al}-\mathrm{Cu}-\mathrm{Li}$ alloy. Science and Technology of Welding and Joining, 14(4): 376-387. https://doi.org/10.1179/136217109X412409

[32] Liu, H.J., Fujii, H., Maeda, M., Nogi, K. (2003). Mechanical properties of friction stir welded joints of $1050-\mathrm{H} 24$ aluminium alloy. Science and Technology Welding and Joining, 8(6): 450-454. https://doi.org/10.1179/136217103225005598

[33] Wang, F.F., Li, W.Y., Shen, J., Hu, S.Y., Santos, J. (2015). Effect of tool rotational speed on the microstructure and mechanical properties of bobbin tool friction stir welding of Al-Li alloy. Materials and Design, 86:

933-940. 
https://doi.org/10.1016/j.matdes.2015.07.096

[34] Hu, Z.L., Wang, X.S., Yuan, S.J. (2012). Quantitative investigation of the tensile plastic deformation characteristic and microstructure for friction stir welded 2024 aluminum alloy. Materials Characterization, 73:
114-123. https://doi.org/10.1016/j.matchar.2012.08.007

[35] Cohen, J., Cohen, P. (1983). Applied Multiple Regression/Correlation Analysis for the Behavioral Sciences. Hillsdale, NJ: Erlbaum. 